\title{
Agility in Teacher Training: Distance Learning During the Covid-19 Pandemic
}

\author{
Yonit Nissim ${ }^{1} \&$ Eitan Simon ${ }^{1,2}$ \\ ${ }^{1}$ Faculty of Education, Ohalo College of Education, Katzrin, Israel \\ ${ }^{2}$ Advanced Learning, Ohalo College of Education, Katzrin, Israel \\ Correspondence: Yonit Nissim, Faculty of Education, Ohalo College of Education, Katzrin, Israel. E-mail: \\ yonitn@ohalo.ac.il
}

Received: June 28, 2020

Accepted: August 9, 2020

Online Published: November 23, 2020

doi:10.5539/ies.v13n12p11

URL: https://doi.org/10.5539/ies.v13n12p11

\begin{abstract}
The outbreak of the Covid-19 pandemic forced the world to respond in new and unconventional ways. Quick thinking and unusual flexibility were required whilst operating under conditions of uncertainty and fear. This article deals with agility in the implementation of distance learning during the Covid-19 pandemic as it occurred at Ohalo College of Education with the outbreak of the epidemic in Israel in March 2020.

Within 48 hours from the moment that Israel's government announced a nation-wide lockdown, the College shifted from frontal teaching and learning to social distancing and distance teaching. The College adopted agile leadership that led to moving 700 courses to distance learning and teaching, with 150 lecturers and 1,500 students in their homes; the semester continued, but differently, in light of the lockdown and limitations ordered by the government. It is clear that such swift organization, executed with maximum flexibility, did not benefit from proper planning and was far perfect. This article offers a look at academic agility as demonstrated during the transition of a college of education to distance learning under emergency conditions. It will be examined through an analysis of survey responses from students. The goal of the survey was to assess students' attitudes toward the implementation of this strategy.
\end{abstract}

Keywords: Covid-19, agility, teacher training, distance learning

\section{Introduction}

\subsection{Agile Leadership During a Crisis}

This article seeks to describe a process in which agile leadership guided an academic organization, namely a college of education in Israel, as it coped with the repercussions of the Covid-19 pandemic, during which all institutions of education and higher learning in the country were closed. A swift solution was required, one that drew on flexibility and agility under uncertain conditions. In particular, it needed to preserve and continue organizational activities, and to move from study at the college to a system of study, teaching, practice and management from afar.

It is important to emphasize that the college transitioned all its components from frontal teaching to emergency-mode distance teaching. We emphasize "emergency-mode" in order to show how this case differs from the general use of the term "distance learning," which refers to a planned online format that implements distance learning pedagogy. With the outbreak of the Coronavirus epidemic in Israel in the beginning of March 2020, unexpected emergency plans were created, whose central expression was emergency-mode distance teaching, requiring an agile organizational response.

Thus, a process was set in motion that moved the physical and frontal activity from all reaches of the campus to educational activity carried out online. This goal enabled teaching and studying to be carried out flexibly (anywhere, at any time), while preserving student and staff health in accordance with the regulations instituted by the government. The speed with which the change was made to distance teaching was unprecedented and remarkable. Staff and support teams immediately joined the teaching faculty to learn about and carry out distance learning.

Ohalo College has some prior experience with moving all of its educational activity online: For the past decade, the 
College has held a special week called "Digital Hanukkah," during which the campus transitions entirely to distance learning, with no lessons taking place on campus. Despite having this experience, the Age of Corona and the transition to distance teaching were not anticipated and therefore the process posed difficulties and challenges. Moreover, the emotional climate during the Coronavirus crisis was rife with fears, anxieties, worries, social distancing, isolation, lockdown and a total reality shift for all those engaged in the present study: administrators, lecturers, students and administrative staff.

Transitions like the one undertaken by Ohalo College at the onset of the pandemic, which faced many organizations around the world, especially challenged the ways that countries, leaders, organizations and individuals needed to think and act in light of the viral threat. To our thinking, there is one idea that is key to understanding and analyzing this behavior, which makes all the difference between success and failure, between responsivity and passivity: namely, agility. Organizations that acted and responded rapidly succeeded in overcoming the various crises posed by the Coronavirus epidemic. Others, who reacted slowly and observed processes from a distance, experienced failure, or even the danger of becoming obsolete.

This is a pioneering study in that other research has not, to the best of our knowledge, been published on the topic of a swift, agile translation to distance learning in higher education during the Covid-19 pandemic. This study aims to shed light on an important issue for institutions of higher learning, in particular those engaged in teacher training.

The research hypothesis was that there will be a connection between students' attitudes toward distance learning and their evaluation of the method of teaching and the lecturers' functioning as well as their evaluation of the college's functioning. This hypothesis will be tested using a mixed-methods approach, employing both quantitative and qualitative measures in a specially-tailored survey.

\subsection{Understanding Distance Learning under Emergency Conditions}

It is important to examine the issue of transitioning to distance learning under emergency circumstances, since this process is quite complex and has received little attention until now. The experiences of students during this time should be examined, in particular, their attitudes and degree of satisfaction with the transition to distance learning due to the restrictions of the Covid-19 pandemic. While such restrictions were imposed on academic institutions around the world, the present article will address the coping of a college of education in Israel.

\subsection{Agility}

It is first important to address our definition of agility: "agility" is one of the most important factors in the survival and development of business organizations in today's dynamic environment. The major characteristic in this environment is change and uncertainty. Current business organizations must cope with a number of issues in order to succeed in the current environment: rapid technological development, expansion of risks, globalization and expectation of privatization and more. Agility creates a competitive advantage that can be optimally sustained with innovation and quality. An agile organization synchronizes processes and private individuals along with advanced technology, and addresses customers' needs based on quality products and services within a relatively short time. This occurs when agility is a systematic, strategic and competitive organizational value to leaders. Most of the researchers have defined agility as an ability that demands active use (Goodarzi et al., 2018)

The concept of agility has its roots in the high-tech industry. Its goal is to succinctly refer to the availability and quickness of reaction with regard to schedules, while also displaying flexibility. Agility in education means the adoption of a flexible attitude toward teaching and learning. This type of teaching and learning approach must demonstrate implementation of change, adopting innovation and leaving conservative or traditional behavior and ways of thinking behind.

Agility represents the need for organizations to act quickly and with flexibility, while displaying adaptability to market changes. This involves the ability and the wisdom to learn from experiences, and to then apply that learning in order to take successful action in new situations. Flexibility is the ability to observe things from various angles and to put forth ideas in the midst of changing directions or correcting information. Adapting includes changes in content, products and services according to need. This approach is reflected in the beliefs of many individuals who support the notion that methods of learning and teaching should be appropriate for education in the modern age, which is informed by a variety of supporting technologies and tools which require making foundational changes to the existing paradigms. These approaches, disseminated in the last decade, discuss " $21^{\text {st }}$ Century Skills" and future-oriented education as an attempt to insert approaches toward thinking outside the box, adopting methodologies from the world of business and high tech and integrating pedagogical and technological innovation into the education system, which is anchored in conservative traditions. 
It is important to note that the college examined in the present study is a teacher-training college under the auspices of the Israeli Ministry of Education and thus, generally speaking, belongs to the public sector. This sector is not usually among the first to adopt changes or undergo ground-breaking processes.

\subsection{Distance Learning}

In recent years, universities, colleges and a variety of institutions have viewed distance learning as an attractive mode of teaching, since it allows more students to register for classes without needing to expand the number of classrooms and teaching facilities. Furthermore, it allows new audiences and populations to be reached, who otherwise may not have continued their higher education or who would not have studied at a specific institution due to distance and travel time. A variety of studies suggest that the main difficulties in distance learning and teaching involve issues with reading texts in digital displays, a sense of isolation, and a lack of cognitive skills necessary for optimal use of online technologies. Researchers note that this can lead to inadequate use of technologies for teaching and learning, and to a lack of pedagogical skills appropriate to distance teaching and learning processes (Atkinson, 1996; Khan, 2001).

Many studies that discuss distance learning seek to evaluate it using the same tools and definitions as those used to measure traditional teaching methods (Hsu et al., 2012). A few studies have found high degrees of satisfaction among students in distance learning courses/programs (Liu, 2010). According to Hecht, distance learning is based on a different understanding of concepts such as authority of knowledge, responsibility for learning, freedom of expression, communal dialogue, and more. Unlike in traditional face-to-face teaching, measuring the effectiveness of distance learning involves differing and sometimes contradictory degrees of satisfaction when it comes to successful use of technologies; lack of satisfaction can be reflected in high rates of dropout from courses (Hecht, 2018).

In contrast to distance learning courses that are planned, designed and tailored to online settings ahead of time, Emergency Remote Teaching (ERT) is a temporary move made to transfer learning to an alternative option due to a crisis. Such a move demands full use of distance learning solutions to enable the teaching that will be carried out in a completely different manner from what was planned as a face-to-face or mixed/hybrid course. During a crisis or time of emergency, the main goal under such circumstances is not to create a strong, ecological education system from scratch, but to provide quick and readily-available temporary access to teaching, learning, and supervision. Understanding ERT in this way, we can begin to study the characteristics of online teaching in the Age of Corona 1.0.

It is important to emphasize that the "agile" approach necessary for ERT may negatively impact the quality of courses and their academic rigor. Numerous studies emphasize that full development of online courses takes at least a number of months to be done thoroughly. The need "to simply get it online" is in direct opposition to the time and effort that is usually devoted to developing a quality online course (Lynn \& Bentrovato, 2011).

Online courses that have been created in times of emergency do not need to offer long-term solutions, like those of MOOCs (Massive Open Online Courses), for example; rather, they are a temporary solution to an immediate problem. The central issue in solutions of this type is the level of accessibility for teaching and learning. It is possible that learning materials are not addressed in the midst of ERT. Rather, the ERT principles concentrate on the design of flexible learning environments that are inclusive and student-centered, so that all students can access and learn from the course materials and activities (Head \& Lockee, 2002).

In recent years, one of the consequences of computer use is the change in traditional relationships between students and the institution, in particular, removing geography as an element that defines and restricts the space and time in which learning processes are carried out. This allows learning to take place without being in a particular place at a specific time, thus inviting the use of innovative models for learning and teaching (Kurtz \& Chen, 2012; Allen, 2013).

Various studies point to the fact that advanced technologies currently allow for easy access and availability of information that can be transformed into knowledge and advancement of learning (Barak, 2007; Barak \& Dori, 2009; Dori, 2007). In recent decades, changes have occurred in learning skills based on the internet (distance learning, internet learning); in parallel, the number of distance courses in institutions of higher learning worldwide has grown (Lee \& Pituch, 2006). Moreover, numerous institutions offer full distance-learning diplomas (Seaman \& Allen, 2010, 2013). Distance learning demands innovative ways of thinking about strategies in institutions of higher education, especially in the field of pedagogy, quality control in education and educational partnerships (O'Shea \& Jones 2004). The growing use of technological skills does not seem to cause teachers to re-examine teaching processes or to take advantage of the new opportunities that these tools offer (Woodmany, 2012). In Israel, since 2008, much effort is invested in using various aids, computers, and 
technology in schools, with the hope that this will ignite radical change in teaching and learning (Rimon, 2012). Thus, it is important to address distance learning as early as during teacher training programs in universities and colleges. Of course, distance teaching and learning has advantages and disadvantages. There is no consensus regarding learner stances towards this learning method and the level of success in achieving high-quality learning outcomes.

\subsection{Research Hypothesis and Questions}

This study sought to examine student satisfaction while implementing "agility" during the dramatic transition carried out by a specific college, from frontal teaching in classrooms to distance teaching, in light of the outbreak of the Covid-19 pandemic.

The research questions were as follows:

1) What are students' attitudes toward distance teaching? This question was examined through three dimensions: the personal perspective (the students' point of view), the lecturers' perspective and the college's perspective.

2) Were the students' attitudes towards distance learning influenced by their assessment of the teaching and functioning of the college during the period of the Coronavirus lockdown?

The research hypothesis was that there will be a connection between students' attitudes towards distance learning and their evaluation of the method of teaching and the lecturers' functioning as well as their evaluation of the college's functioning.

\section{Method}

The study employed mixed methods, utilizing qualitative and quantitative measures. The research was based upon an attitude survey built especially for this study, which was distributed via Google Drive to all of the college's students, numbering approximately 1,500. The students were enrolled in various years of study and departments, including B. Ed. and M. Ed. studies as well as a "career-change" track to become teachers. Anonymity was maintained in the responses due to ethical considerations.

The questionnaire underwent face validation, and was examined by three experts holding doctorates in education. Created especially for this study, it sought to examine attitudes of students toward distance learning during the period of the Coronavirus lockdown beginning in March 2020. It considered three components: reflective feedback from students to express their attitude towards themselves, their attitude toward the college's general functioning, and their attitude toward the lecturers' functioning.

\subsection{Participant Characteristics}

183 student participants participated in the study. 154 of these were female $(84.2 \%)$ and 29 males (15.8\%), ages 18 to 57 (average 27.77 ). More than half of the participants were unmarried $(55.7 \%)$ and most engaged in regular study tracks (rather than the "career-change" track) $(69.9 \%)$. Table 1 presents the distribution of the participants according to demographic variables.

Table 1. Demographic variables of participants

\begin{tabular}{lcccccc}
\hline & $\mathrm{N}$ & $\%$ & Minimum & Maximum & Average & Standard Deviation \\
\hline Age & & & 18.00 & 57.50 & 27.77 & 8.12 \\
\hline Gender & & & & & & \\
\hline Male & 29 & 15.8 & & & & \\
\hline Female & 154 & 84.2 & & & \\
\hline Marital Status & & & & & \\
\hline Unmarried & 102 & 55.7 & & & \\
\hline Married & 81 & 44.3 & & & \\
\hline Study Track & & & & & \\
\hline Continuing Education & 32 & 17.5 & & & \\
\hline Regular & 128 & 69.9 & & & \\
\hline M.Ed. & 23 & 12.6 & & & \\
\hline Year of Study & & & & & \\
\hline Year 1 & 59 & 32.8 & & & \\
\hline Year 2 & 66 & 36.7 & & & \\
\hline
\end{tabular}




\begin{tabular}{lcc}
\hline Year 3 & 35 & 19.4 \\
\hline Year 4 & 20 & 11.1 \\
\hline Own Computer & & \\
\hline Yes & 165 & 90.2 \\
\hline No & 18 & 9.8 \\
\hline
\end{tabular}

\subsection{Research Tool}

The questionnaire included 16 statements, most of which used a five-point Likert scale (all besides Statement 11), that examined three topics: The student's attitudes towards distance learning; evaluation of the method of teaching and the lecturers' functioning; and evaluation of the college's functioning.

The first topic ("students' attitudes towards distance learning") included eight statements: 1, 3, 4, 6, 7, 10, 11, and 16, while statements $1,3,4,6,7$, and 16 , were written in language that expresses positive attitudes towards distance learning. Statement 10 examined the level of difficulty in distance learning, and thus it had a reversed scale. Statement 11 examined the level of deviation, when the range of answers were: "No", "Perhaps", and "Yes." It was decided that the "Yes" answer would be given one point, the "Perhaps" answer would be given three points and the "No" answer would be given 5 points. Each participant's answers were checked for responses to these 8 statements and thus the scale for "student attitudes towards distance learning" was defined.

The questionnaire included an additional six statements $(2,5,8,9,12$, and 15), $1-5$ on the Likert scale, that examined the evaluation of "the method of teaching and the lecturers' functioning." For these statements, higher values represent high appraisal. The average of these 6 answers was calculated for each participant, and that how this scale was judged.

The participants answered an additional two statements (13 and14) on the $1-5$ Likert scale that examined "evaluation of the college's functioning." In these statements, the higher values on the scale indicated a more positive evaluation. The average of these two answers was calculated for each participant, and that how this scale was judged. Table 2 presents general characteristics of two indices.

A qualitative portion of the questionnaire consisted of an open question inviting students' remarks. This section went through a content analysis and categorization into verbal categories.

Table 2. General characteristics, average, standard deviation and reliability of the study indices $(\mathrm{N}=18.3)$

\begin{tabular}{lcccccc}
\hline Index & $\begin{array}{c}\text { No. of } \\
\text { Statements }\end{array}$ & Minimum & Maximum & Average & $\begin{array}{c}\text { Standard } \\
\text { Deviation }\end{array}$ & \begin{tabular}{c}
$a$ \\
\hline Attitudes towards distance learning
\end{tabular} \\
\hline $\begin{array}{l}\text { Assessment of the method of teaching and the } \\
\text { lecturers' functioning }\end{array}$ & 6 & 1.00 & 5.00 & 2.74 & .95 & .857 \\
\hline Assessment of the college's functioning & 2 & 1.00 & 5.00 & 3.12 & .97 & .887 \\
\hline
\end{tabular}

The reliability of the indices was examined according to Alpha-Cronbach (a) and was found to be high in the first two indices, a fact that is characteristic of the extent of stability and consistency in the participants' answers to each of the statements. In contrast, the item of data examining the reliability of evaluation of the college's functioning was found to be low and indicates the low degree of stability and consistency in the participants' answers to the two statements in this measure.

\section{Results}

\subsection{Quantitative Analysis}

In order to test the research hypothesis, Pearson tests were carried out between results for the three categories ("Attitudes towards distance learning," "evaluation of the method of teaching and the lecturers' functioning," and "evaluation of the college's functioning").

A positive connection at a significantly high level was found $(\mathrm{r}=0.738, \mathrm{p}<0.01)$ between the measure of attitudes towards distance learning and that of the evaluation of the method of teaching and the lecturers' functioning as well as the functioning of the college, such that the more the student values the method of teaching and the lecturers' functioning, the better their attitudes towards distance learning. 


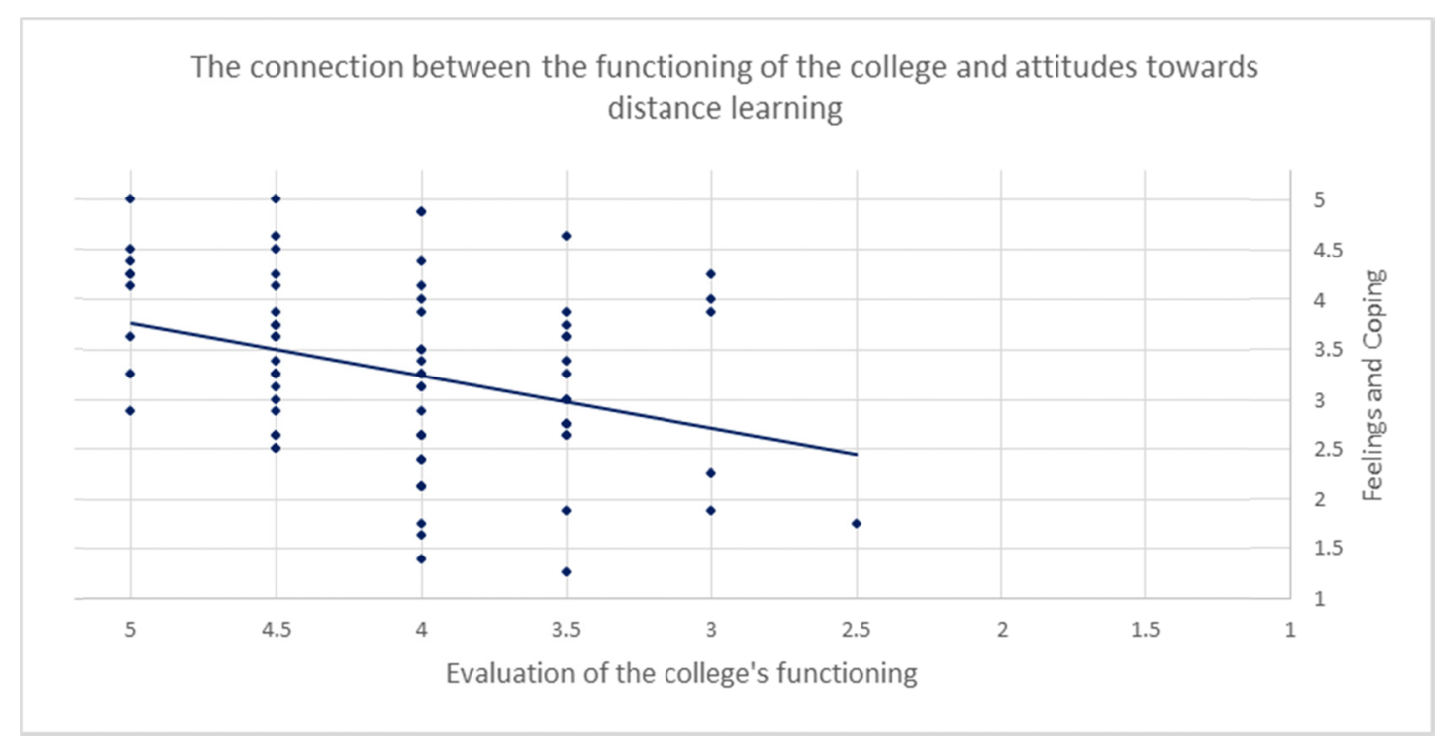

Figure 1. Connection between method of teaching and lecturers' functioning and attitudes towards distance learning

Similarly, it was found that there is a significant, moderately positive connection $(r=0.506, p<0.01)$ between the measure of attitudes towards distance learning and evaluation of the functioning of the college, such that the more the student appreciates the functioning of the college, the better their attitudes towards distance learning.

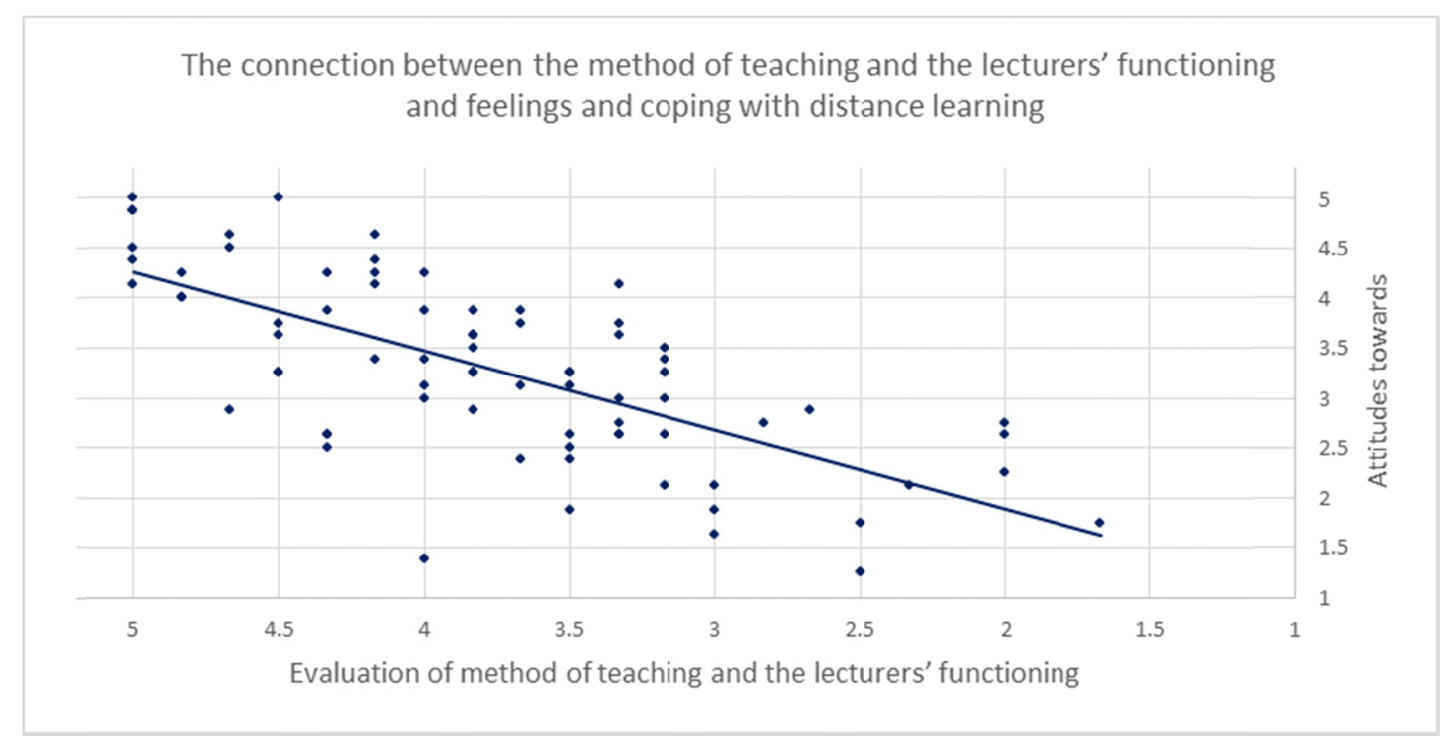

Figure 2. Connection between functioning of the college and attitudes towards distance learning

\subsubsection{Age}

In order to examine the connection between the age of the participants and the indices of the study, additional Pearson tests were carried out. It was found that there is a significant, weak, positive connection $(\mathrm{r}+0.159$, $\mathrm{p}<0.05$ ) between the participant's age and the level of evaluation about the method of teaching and functioning of the lecturers, such that the older the student was, the more he valued his lecturers' functioning. There is also a significant, weak, positive connection $(\mathrm{r}=0.177, \mathrm{p}<0.05)$ between the age of the participant and evaluation of the functioning of the college, such that the older the student was, the more they valued the functioning of the college. In contrast, no significant connection was found between the age of the participant and attitudes towards 
distance learning $(r=0.118, p>0.05)$, such that different the participant's age did not affect their attitude towards distance learning.

\subsubsection{Owning a Computer}

The examination of the differences in the three indices of the study between participants who have a computer at home and those who do not have a computer, was done through $t$ tests for objective samples. Table 3 below presents the averages for the two groups and the results of the tests.

Table 3. Difference according to whether participant owns a computer and results of t-tests $(n=183)$

\begin{tabular}{lccccc}
\hline & \multicolumn{2}{c}{ No Computer $(\mathrm{N}=18)$} & \multicolumn{3}{c}{ Computer (N=165) } \\
\hline Index & Average & Standard Deviation & Average & Standard Deviation & $\mathrm{t}$ \\
\hline Attitudes towards distance learning & 2.31 & 0.79 & 2.79 & 0.76 & $2.03^{*}$ \\
Assessment of method of teaching and lecturer's functioning & 2.55 & 0.94 & 3.19 & 0.96 & $2.70^{* *}$ \\
Assessment of college's functioning & 2.94 & 0.94 & 3.39 & 0.93 & 1.93 \\
\hline
\end{tabular}

$* \mathrm{p}<0.05$.

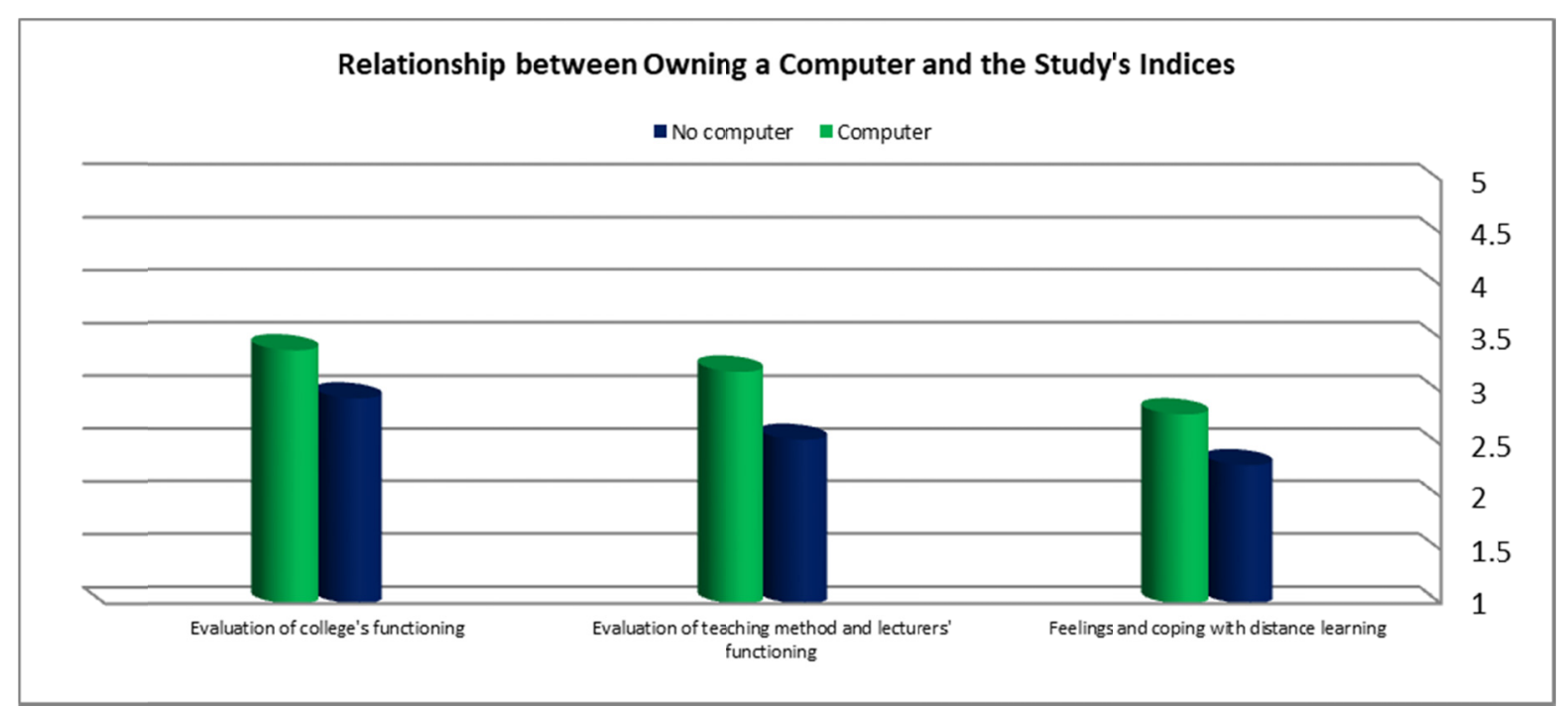

Figure 3. Relationship between participant owning a computer and the study's indices

It was found that attitudes towards distance learning among participants with a computer were significantly better than among participants who did not have a computer: $\mathrm{p}<0.05, \mathrm{t}(181)=2.03$. It was also found that computer owners evaluate the method of teaching and the lecturers' functioning significantly better than those without computers: $p>0.01, t(181)=2.70$, and additionally, they evaluate the college's functioning better, although the results are not significant: $\mathrm{p}>0.05, \mathrm{t}(181)=1.93$.

\subsubsection{Marital Status}

In order to examine the differences between the study's three indices among the married and unmarried participants, $t$ tests were carried out for independent samples. Table 4 below presents the average among the two groups and the results of the tests.

Table 4. Differences according to marital status and results of t-tests $(\mathrm{n}=183)$

\begin{tabular}{lccccc}
\hline & Unmarried $(\mathrm{N}=102)$ & & Married $(\mathrm{N}=81)$ \\
\hline Index Deviation & Average & Standard & Average & Standard Deviation & $\mathrm{t}$ \\
\hline Attitudes toward distance learning & 2.62 & 0.83 & 2.90 & 1.07 & $2.01^{*}$ \\
Evaluation of method of teaching and lecturers' functioning & 3.02 & 0.89 & 3.25 & 1.06 & 1.57 \\
Evaluation of college's functioning & 3.30 & 0.90 & 3.40 & 1.00 & 0.70 \\
\hline
\end{tabular}
$* \mathrm{p}<0.05$. 


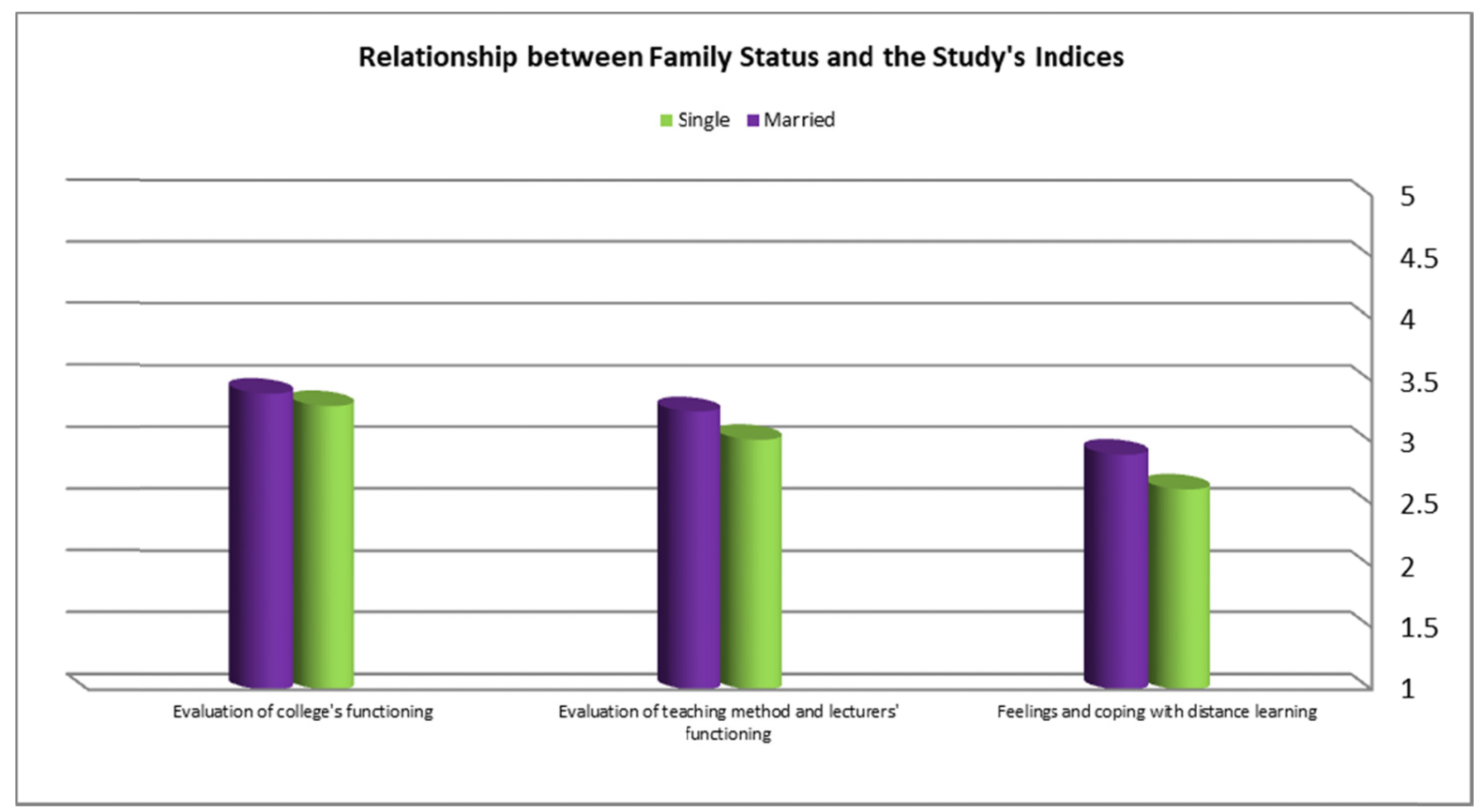

Figure 4. Relationship between marital status and the study's indices

It was found significant that attitudes towards distance learning among married participants were better than among unmarried participants: $\mathrm{p}<0.05, \mathrm{t}(181)=201$. It was also found that married participants evaluated the method of teaching and the lecturers' functioning more highly than the unmarried participants, though not significantly: $\mathrm{p}>0.05, \mathrm{t}(181)=1.57$ and that they evaluated the college's functioning better, though not significantly: $\mathrm{p}>0.05, \mathrm{t}(181)=0.07$.

\subsubsection{Gender}

In order to examine the differences between the study's three indices among women and men, t-tests were carried out for independent samples. Table 5 presents the averages among the two groups and the test results.

Table 5. Differences according to gender and t-test results ( $\mathrm{n}=183)$ '

\begin{tabular}{|c|c|c|c|c|c|}
\hline \multirow[b]{2}{*}{ Index } & \multicolumn{2}{|c|}{ Male $(\mathrm{N}=29)$} & \multicolumn{3}{|c|}{ Female $(\mathrm{N}=154)$} \\
\hline & Average & Standard Deviation & Average & Standard Deviation & $\mathrm{t}$ \\
\hline Attitudes toward distance learning & 2.62 & 1.01 & 2.76 & 0.94 & 0.74 \\
\hline Evaluation of method of teaching and lecturers' functioning & 2.99 & 0.77 & 3.15 & 1.01 & 0.79 \\
\hline Evaluation of college's functioning & 3.34 & 0.89 & 3.35 & 0.95 & 0.01 \\
\hline
\end{tabular}




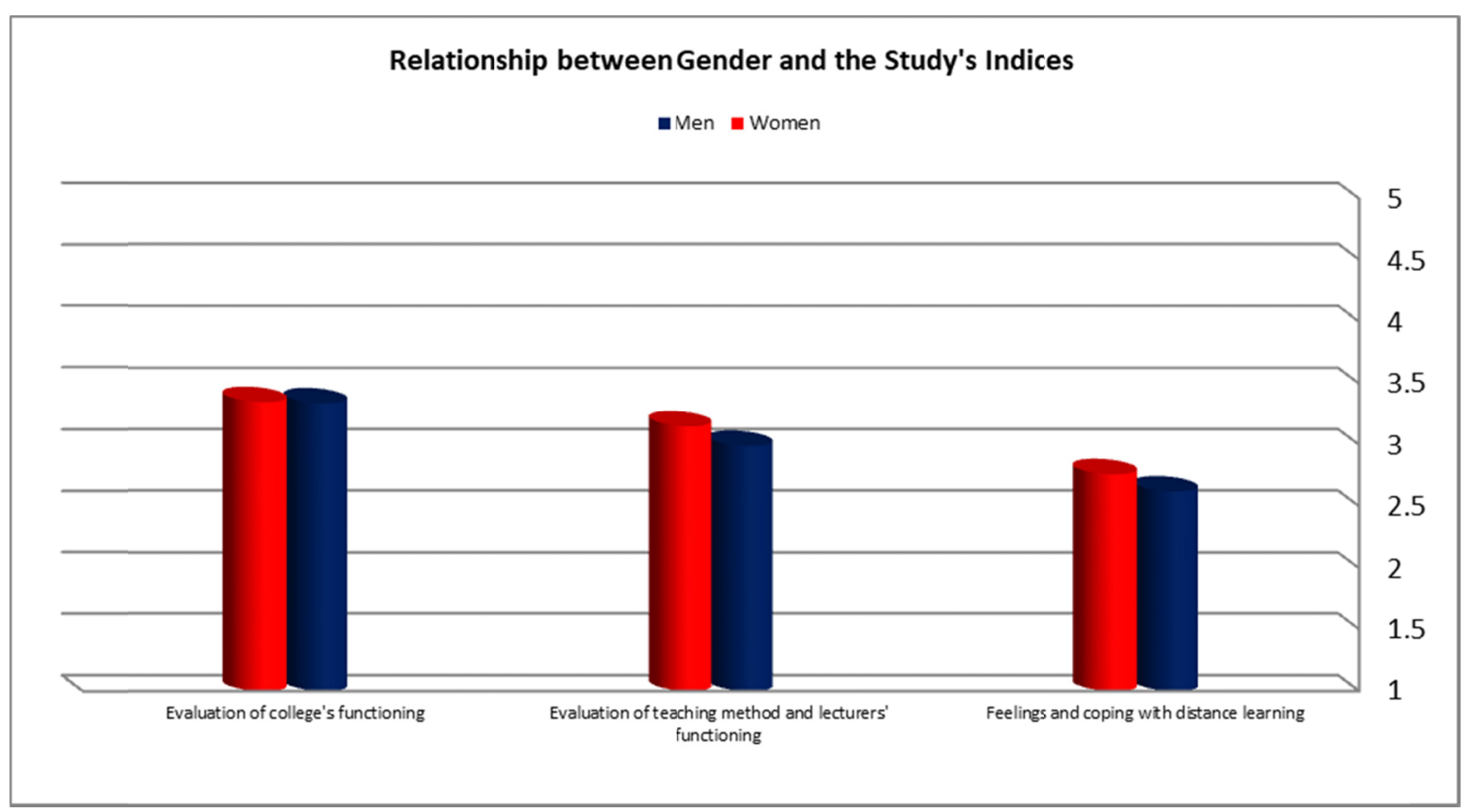

Figure 5. Relationship between gender and the study's indices

As seen, there are no differences noted between men and women according to the three study indices.

\subsubsection{Study Track}

In order to examine the differences in the three research indices according to study tracks, analysis of variance was carried out. Table 6 below presents the averages among the three study tracks and the test results.

Table 6. Differences according to study track and results of analysis of variance $(\mathrm{n}=183)$

\begin{tabular}{lccccccc}
\hline & \multicolumn{2}{c}{$\begin{array}{c}\text { Continuing Education } \\
(\mathrm{N}=32)\end{array}$} & \multicolumn{2}{c}{ Regular (N=128) } & \multicolumn{2}{c}{ M.Ed. } \\
\hline Index & Average & Stand. & Average & $\begin{array}{c}\text { Stand. } \\
\text { Dev. }\end{array}$ & Average & $\begin{array}{c}\text { Stand. } \\
\text { Dev. }\end{array}$ & F \\
\hline $\begin{array}{l}\text { Attitudes toward distance learning } \\
\begin{array}{l}\text { Evaluation of method of teaching and lecturers' } \\
\text { functioning }\end{array}\end{array}$ & 3.19 & .87 & 2.62 & .95 & 2.81 & .89 & $4.92^{* *}$ \\
\begin{tabular}{l} 
Evaluation of college's functioning \\
\hline
\end{tabular} & 3.53 & .82 & 2.99 & .97 & 3.28 & 1.06 & $4.40^{*}$ \\
& 3.41 & .89 & 3.31 & .95 & 3.46 & .99 & 0.30 \\
\hline
\end{tabular}




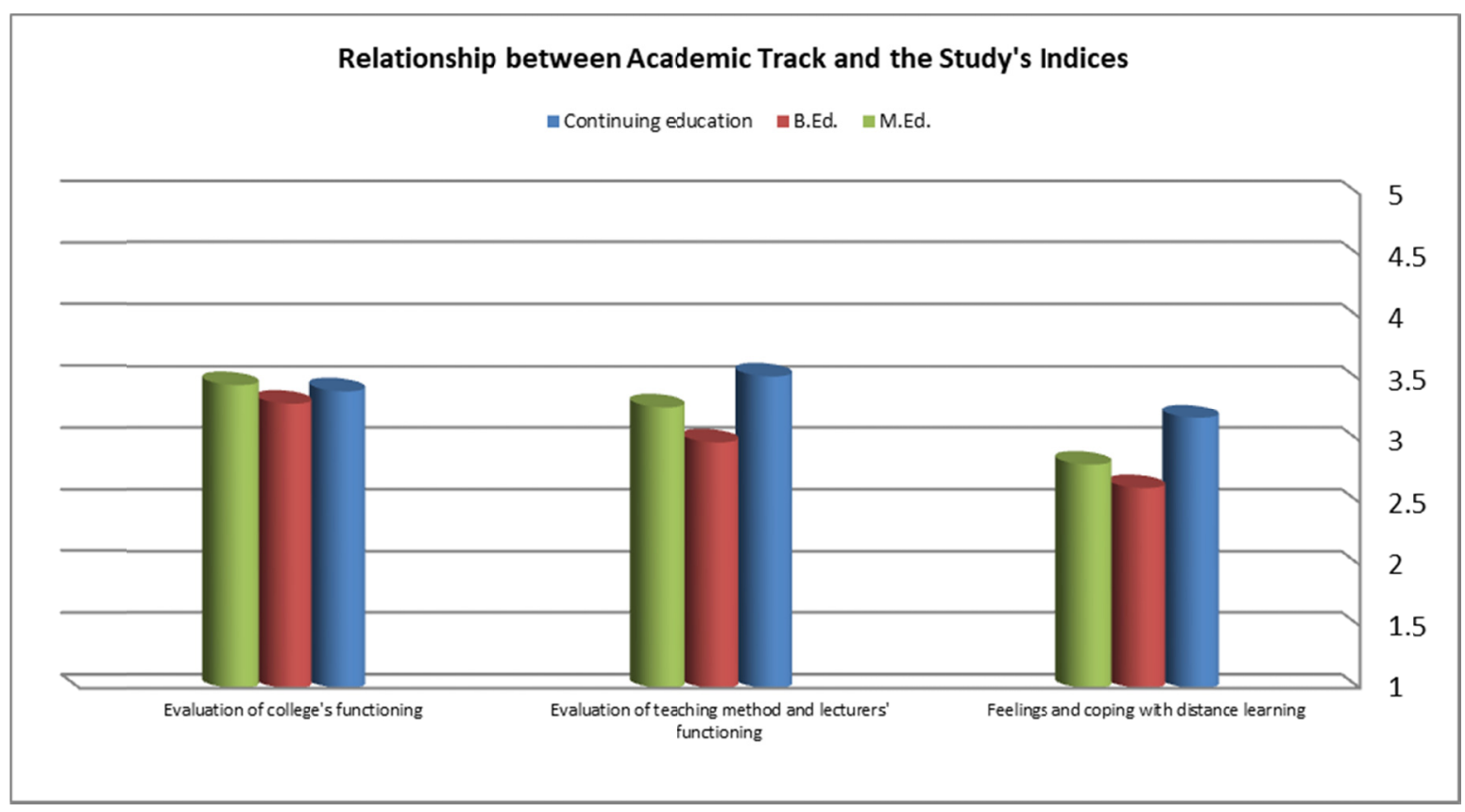

Figure 6. Relationship between academic track and the study's indices

As can be seen, the satisfaction of the participants in continuing education track was better than those of participants in regular or M.A studies. This difference is significant: $p<0.01, F(2,180)=4.92$. Moreover, the students in regular studies evaluate the method of teaching and the lecturers' functioning as significantly lower than those in continuing education or M.Ed.: $\mathrm{p}<0.05, \mathrm{~F}(2,180)=4.40$. No differences were found in evaluation of the functioning of the college.

\subsubsection{Year of Study}

The examination of the differences among the three indices of the study according to year of study, was carried out using analysis of variance. Table 7 below presents the averages among the three groups of study tracks and the test results.

Table 7. Differences according to gender and results of $\mathrm{t}$-tests $(\mathrm{n}=183)$

\begin{tabular}{|c|c|c|c|c|c|}
\hline \multirow[b]{2}{*}{ Index } & \multicolumn{2}{|c|}{ First Year $(\mathrm{N}=59)$} & \multicolumn{3}{|c|}{ Second Year $(\mathrm{N}=66)$} \\
\hline & Average & Stand. Dev. & Average & & Stand. Dev. \\
\hline Attitudes toward distance learning & 2.88 & .81 & 2.71 & & 1.01 \\
\hline Evaluation of method of teaching and lecturers' functioning & 3.38 & .76 & 3.01 & & 1.11 \\
\hline \multirow[t]{2}{*}{ Evaluation of college's functioning } & 3.64 & .72 & 3.27 & & 1.00 \\
\hline & \multicolumn{2}{|c|}{ Third Year $(\mathrm{N}=35)$} & \multicolumn{3}{|c|}{ Fourth Year $(\mathrm{N}=20)$} \\
\hline Index & Average & Stand. Dev. & Average & Stand. Dev. & $\mathrm{F}$ \\
\hline Attitudes toward distance learning & 2.48 & .88 & 2.96 & 1.17 & 1.71 \\
\hline Evaluation of method of teaching and lecturers' functioning & 2.86 & .89 & 3.19 & 1.10 & 2.62 \\
\hline Evaluation of college's functioning & 2.89 & 1.00 & 3.50 & .90 & $5.33^{* *}$ \\
\hline
\end{tabular}

No differences were found according to study year with regards to attitudes towards distance learning: $p>0.05$, $\mathrm{F}(3,176)=1.71$. Moreover, there are no differences according to study year regarding evaluation of method of teaching and lecturers' functioning: $\mathrm{p}>0.05, \mathrm{~F}(3,176)=2.62$. In contrast, differences were found in evaluation of the college's functioning: $\mathrm{p}<0.01, \mathrm{~F}(3,176)=5.33$, with fourth year students having a significantly lower evaluation as compared to first, second and third year students.

All of the findings shown above will be analyzed below in congruence with distance learning processes and the "agility" process that occurred at the time of the outbreak of the Coronavirus epidemic outbreak. 


\subsection{Qualitative Analysis of Content}

In the qualitative portion of the questionnaire, 103 participants answered the open-ended question.

The responses were read a number of times. Initial encoding was carried out to create content categories. In the first stage, two central categories were found: positive evaluation of distance learning (15 statements) and critical evaluation ( 88 statements). Most of the responses described a wide variety of difficulties.

Sub-categories were identified: work load, domestic challenges (children, household chores, economic burden), difficult focusing, being accustomed to frontal learning and having a hard time transitioning to distance learning, emotional difficulties associated with the Coronavirus crisis, and general lack of satisfaction relating to a combination of different reasons. A selection of examples from each category will be presented below.

It is apparent that most of the critical responses emerged from the complex nature of the Coronavirus epidemic period and from the general climate caused by its outbreak, including restrictions such as quarantine, social distancing, and lockdown, and particularly the acute state of uncertainty. Beyond this, students had to cope with the burden of academic tasks, most of which were unpredictable. When students study in classrooms on campus, they are usually somewhat passive, and it is the lecturer or advisor who takes the central role in getting the material across, or in leading an active learning session. In distance learning/teaching, there are more tasks given in a non-synchronous manner.

We identified 5 major categories in the qualitative content analysis:

1) Efficiency and savings as a result of distance learning

2) Recognizing the benefits of distance learning

3) General criticism and ideas for improvement

4) Distraction and lack of focus

5) Challenges arising from domestic issues during lockdown

Quotations reflecting each of these categories have been brought in their original form (translated from the Hebrew) in the following sections.

1) Efficiency and savings as a result of distance learning

A female student noted: "Distance learning is much easier. It saves time and money on travel and I am more attentive when I'm comfortable in an armchair at home."

Another female student mentioned this same point: "I don't have any complaints towards the lecturers about the variety in the lessons and I even think distance learning is far better and that we don't need to waste gas and time. Nowadays, it's possible to do everything from afar."

Another female student emphasized the advantages distance learning has for her as a new mother: "I really love distance learning and actually prefer it. I gave birth to a baby boy three months ago and the distance learning makes it much easier for me because I don't have to travel an hour and a half to the college. I would be glad if they allowed this to continue after the Corona crisis is over."

Another responded that she was pleased, but also had fears about the uncertainty to come once the crisis passes: "I hope that this learning that we're doing now will count as if we had been in the college, that we won't have to come in to make up for it and that we can complete the semester on the original date. This is my final year of studies for the diploma and I really hope it won't be delayed because of the situation, because most of the courses I'm taking are taught well even online."

2) Recognizing the benefits of distance learning

Others evaluated distance learning while applying critical thinking to the methods of teaching, what they receive, and the benefits....

"The distance learning is excellent. I'm able to understand, only with those who lecture and explain the way they should. But a few of the lecturers give a task or two every week and they don't make an effort to give a lecture online to explain [the material]."

Another female student noted: "I think this is an excellent opportunity to evaluate distance learning: to learn about the advantages and disadvantages of varying the learning and about students'satisfaction. For us as students we experience this from the other vantage point, too."

A male student noted the advantages alongside a desire to return to normalcy: 
"This college is great: the lecturers really invest in us and do everything so that we'll succeed, but I feel like there are too many tasks, and for me personally it's hard. For example, in anatomy and the study of cells, in order to study and take the test, I personally need to be in a room with a lecturer and not 'live [online].' But this is the situation and so unfortunately there's no choice and I have to cope with it; I hope we return very soon."

3) General criticism and ideas for improvement

"Not all of the lecturers teach online; some only upload presentations and say 'study this.' In distance learning, they are supposed to record themselves or film themselves and send it to us so we can understand the presentations."

"Instead of distance learning, they could have changed the approach and given some challenging and interesting assignments...thinking outside the box. Lectures could be recorded professionally and more interestingly in a simulation center... This is my opinion, after being disappointed by the learning via ZOOM."

With regard to the main difficulties that were mentioned, a number of primary categories were noted:

4) Distraction and lack of focus

"It's really hard because of course we're at home, and I am distracted by every little thing, but it's also convenient for me because I don't need to get up really early in the morning to get organized and go to the college and that's really helpful. Anyone who has attention issues should go to a room by themselves and listen to the lessons; there's a solution for everything."

Another female student noted that:

"It's hard to sit and concentrate for an hour and a half like a regular lecture; it's not a regular lecture in a classroom. I'm in front of a computer and that's hard; maybe if they shortened the lecture that would help."

"The situation is difficult as it is, and the distance learning makes it harder, especially if you have ADHD. Every lecturer thinks they're the only one giving you assignments."

The following category was prominent, with a large number of reactions (40):

5) Challenges arising from domestic issues during lockdown

A female first-year student noted:

"It's really hard that there is still no interaction between students and no personal interaction with the lecturers, we don't know them or each other. I still don't understand 'Orbit Live'well enough, as a model, and I'm not able to find articles. All of this makes it harder with distance learning. I would like if you could give us more consideration. Moreover, as the mother of a child, it's hard to follow the different assignments and to know when to submit them; it's difficult to be synchronized in distance learning, and to listen without being disturbed. I'm looking forward to going back."

Another female student addressed the need to have turned on the computer camera during a ZOOM meeting:

"We would like there to be more consideration. All in all, we feel from minute to minute that there is progress in the online learning process. Regarding the issue of being required to turn on the camera - this is something that can embarrass some of us, especially if we're not alone at home."

Numerous female and male students noted the fact that they must care for their children during lockdown and are not available for synchronous learning:

"Be considerate of students who have children and whose partners are working; they are alone with the children and cannot log onto lessons or spend time on assignments when there are so many assignments. It doesn't make any sense!!!!! Why do you have to give an assignment for every lesson?"

"We're in a complicated situation right now and of course we should continue with routine and our academic studies, but I also, personally have a young daughter at home and that makes it hard, along with all of the assignments and the ZOOM lessons."

"I'm in the career-change track, a mother of 2, my youngest is two and a half, I am a teacher and educator myself. It doesn't make sense that in addition to all of this, I have to do assignments that lecturers send or participate in ZOOM lessons, when I also have lessons to teach to my students, not to mention taking care of my children at home when my husband is an essential worker and is out of the house most of the day. Please be more considerate of us in the coming weeks. If you can that will help very much ... thank you in advance."

These few examples represent many responses in this vein. They testify to the difficulties the students face, most of which stem from the surprising way that the Coronavirus epidemic came about, making distance learning 
necessary. This was no less surprising to the faculty, who were required to adapt various processes, and to design the educational setting in a different way, all while in front of computer screens.

\section{Discussion}

Distance learning has advantages and disadvantages for students, faculty, and colleges. Institutions that invest in processes of distance learning on a regular basis will have a good foundation from which to rapidly (within days) transition to distance learning. In the short-term, there is no expectation that this transition will create additional educational benefit beyond allowing for studies to continue on as normally as possible, while preserving a certain routine. It is important to highlight the sudden nature of Coronavirus outbreak; and instructions were given for immediate change, on the backdrop of a rapidly shifting reality.

At Ohalo College, the agile change to distance teaching took place within 48 hours (from the instructions on the quarantine) for most courses, in a range of fields and disciplines. Lecturers were not given time to prepare and organize the learning sites and to create learning materials that were pedagogically appropriate for the online setting. In this context, it was expected that the quality of teaching would be less effective in the short-term than the lessons and courses that had been planned and taught in the usual way. Nonetheless, the demands for social distancing forced online or hybrid approaches to be adopted for the length of an entire semester.

This study sought to examine how distance teaching was implemented at Ohalo College of Education, in the Age of Corona. This agile process was conducted in light of the regulations imposed on the college.

Two central research questions were posed:

1) What are students' attitudes toward distance teaching? This question was examined through three dimensions: the personal perspective (students' point of view), the lecturers' perspective and the college's perspective.

2) Were the students' attitudes towards distance learning influenced by their assessment of the teaching and functioning of the college during the Coronavirus period?

The research hypothesis was that a connection would be found between students' attitudes towards distance learning and their evaluation of the method of teaching and the lecturers' functioning as well as their evaluation of the college's functioning.

This assumption was reinforced by the responses to the research questionnaire, processed through various statistical tests, presented above. The study's conclusions are as follows:

1) The answers demonstrated the very positive and significant connection $(\mathrm{p}<0.01, \mathrm{r}=0.738)$ between the index of attitudes towards distance learning and the index of evaluation of the method of teaching and the lecturers' functioning, such that, the more a student values the method of teaching and the lecturers' functioning, the better their attitudes towards distance learning.

2) A moderately positive significant connection $(\mathrm{p}<0.01, \mathrm{r}=0.506)$ was found between the index of attitudes towards distance learning and the index of evaluation of the college's functioning, such that the more a student values the college's functioning, the better their attitudes towards distance learning were.

3) Additionally, the older the students, the more they valued their lecturers' functioning. A positive, weak, significant connection $(\mathrm{p}<0.05, \mathrm{r}=0.177)$ was found between the age of the participant and the index of valuing the college's functioning, in such a way that, the older the students, the more they value the college's functioning. In contrast, there was no significant connection found between participant age and the index of attitudes towards distance learning $(\mathrm{p}>0.05, \mathrm{r}=0.118)$. It was found that participants in regular studies valued the method of teaching and the lecturers' functioning less than participants in continuing education or M.Ed. and this was statistically significant: $\mathrm{p}<0.05, \mathrm{~F}(2,180)=4.40$. No differences were found in evaluation of the college's functioning.

4) No differences were found among students in different years of study in terms of attitudes toward distance learning: $->0.05, F(3,176)=1.71$, and thus no differences were found based on year of study in evaluating the method of teaching and the lecturers' functioning: $\mathrm{p}>0.05, \mathrm{~F}(3,176)=2.62$. In contrast, differences were found in evaluating the college's functioning: $\mathrm{p}<0.01, \mathrm{~F}(3,176)=5.33$, where third year students evaluate the college's functioning significantly lower, as opposed to first, second or fourth year students. It is possible that the reason for this is that third year students generally spend a lot of their time in the field in teaching practicum, in schools and kindergartens, spending less time at the college. The outbreak of the Coronavirus epidemic forced them to study more than at other times, which was done in order to both "practice" distance teaching and to study in various courses. The burden and the load placed on the third year was doubled. 
5) The attitudes towards distance learning among married students were significantly better than for unmarried students: $\mathrm{p}<0.05, \mathrm{t}(181)=2.01$. It was also found that married students evaluated the method of teaching and the lecturers' functioning more favorably than the unmarried students, but not significantly: $p>0.05$, $\mathrm{t}(181)=1.57$, and that they evaluated the college more favorably, though not significantly: $\mathrm{p}>0.05$, $\mathrm{t}(181)=0.70$.

6) In contrast, in the qualitative section, a number of answers (40) noted a variety of difficulties and complications that emerged due to the students' having to care for their own children, making it difficult for them to create time and availability for distance learning.

7) An additional item of data indicates that there were no differences between the men and the women in the three study indices.

8) In general, it is noticeable that the students had substantial difficulty coping with distance learning. This index received the lowest score (2.6) in all of the categories. The reason for this is embedded in a wide variety of circumstances. A broader explanation and description of this can be found in the qualitative analysis of the verbal responses.

9) The qualitative analysis demonstrated that there were a wide variety of statements in response to the open-ended question. We identified 5 major categories in the qualitative content analysis: 1 . efficiency and savings as a result of distance learning, 2. recognizing the benefits of distance learning, 3. general criticism and ideas for improvement, 4. distraction and lack of concentration, and 5. challenges arising from household/family issues during lockdown. From the analysis of verbal statements, it appears that the large number of answers (104) points to the fact that it was important to students to have their voices heard. The responses were detailed (each answer included at least one written paragraph). Analysis of the various responses points to a clear initial division into positive attitudes alongside those highlighting the difficulty that students describe during distance learning in this period. Analysis of the content indicates many different reasons that made it difficult for the students to deal with distance learning. Among them we identified a number of central content categories: a positive attitude toward distance learning and identification of advantages ( 15 statements) and a critical attitude ( 88 statements). Most of the reactions described a wide range of difficulties. Sub-categories were found: feeling too busy and overwhelmed, household issues (children, housework, economic problems), concentration, the familiarity of frontal learning and the difficulty of transitioning to distance learning, and emotional issues, stemming from the complexity of this period of the Corona crisis, as well as a general lack of satisfaction relating to a combination of several factors.

10) We surmise that the longer the exposure to distance teaching and learning continues, the more students and staff will be able to adjust to the change and to feel comfortable with this model. Following this adjustment, we anticipate that some students and lecturers will invest in resources to shift their face-to-face learning to the online setting, while preserving or even raising their quality. These investments could include partnering with designers or private companies that design online courses and rapid training of staff members to transition to online courses. Although online courses allow for more students, they can take all semester or up to a year to be properly developed; plans of this kind can enhance the students' approach and improve their results, and thus possibly lead to expanded adoption of these technologies even after the Coronavirus crisis is over. In order to facilitate online and hybrid learning at a high level, colleges need to be prepared in the best possible way to deal with distance learning of such a large scope.

\section{Conclusion}

From the findings of this study, it emerges that the college acted with agility in light of the unique circumstances posed by the Covid-19 epidemic. This posed an advantage, allowing for the transfer of educational activity to distance learning within 48 hours, for all of the courses at the college offered by all lecturers, with the participation of students from a variety of academic tracks (regular, career-change and M.Ed.). This alternative provided a rapid though imperfect solution to the challenge. The alternative would have been to suspend studies altogether or at least for a number of weeks in order to get organized, make in-depth academic preparations, and develop hundreds of online courses (the establishment of a quality online course takes, on average, half a year). This would likely have resulted in greater student satisfaction. However, wasted time and lost momentum would also be problematic; indeed the role of maintaining that momentum was to strengthen and continue to reinforce the process of organized teacher training, as an anchor for establishing a "Corona routine," in contrast to the alternative of very slow implementation that would benefit from somewhat improved academic quality. The consideration that came prior to the decision was to establish a consistent and coherent learning routine as much as possible in light of the 
rapidly-shifting reality to create some semblance of a routine through distance learning. It is important to remember that the institution being examined is a training college for teachers and educators. Hence, processes that the students experienced during this time will prompt reflection and insights informing their behavior as future teachers. The same students who experienced the online semester during the Corona epidemic will have gained experience that will be relevant if and when they experience a period of emergency as teachers and educators. That is to say, the experiment and the experience have added value to their training process for coping with uncertainty, emergencies and distress.

The findings indicate that student satisfaction was moderate. The emotional conditions created by the Corona crisis - feelings of displacement, uncertainty, fears and anxieties (a topic that has yet to be studied since the epidemic is fresh and still ongoing) - significantly impact the findings. As opposed to experiences of distance learning courses that are well-planned, designed and tailored to the online format in advance, Emergency Distance Learning (ERT) is a temporary transition that moves teaching to a different format due to a crisis situation. It involves full use of distance teaching solutions for teaching or educating, where lessons are given in a completely different manner than what had been planned as face-to-face meetings or mixed/hybrid courses. In a crisis or emergency situation, the main goal under the circumstances is not to create a strong ecological educational system from scratch but to provide quick, temporary, readily-available and accessible teaching and guidance.

Furthermore, when a student registers for an online course, they are agreeing to participate in a course with a particular format. They enter into the situation while clear on the expectations regarding distance learning and assignments, demands, and environment, as laid out in an organized syllabus. In contrast, the situation created by the Coronavirus epidemic intensified the scope of uncertainty and instability and thus it is understandable that student satisfaction was moderate.

\section{Recommendations}

1) One of the core insights in this study is that institutions of higher education, and schools of education in particular, should prepare for emergency situations as much as possible.

2) Namely, we suggest preparing emergency strategies, contingency plans, etc.

3) When training institutions create dramatic changes, all the more so in times of emergency, it is appropriate to strengthen ties with the students, and for lecturers to mediate what is happening. It is recommended to organize, as much as possible, methodical systems of support to provide answers for various difficulties that arise (financial issues, stress, overwhelm, lack of concentration, etc.).

4) It is important to understand beforehand that agile processes can create satisfactory solutions. However, while the solutions may be rapid and flexible - agile - there will be a price to pay in terms of quality.

5) The significant insight arising from this study is that the greater the students' appreciation for the college's functioning, the greater their satisfaction with distance learning. This is worth emphasizing; it is important to empower the students and to listen to their thoughts and suggestions with regards to distance learning. One of the lessons learned during the Coronavirus crisis is that agile functioning can be sufficient in order to preserve a continuum of learning and to continue activity via an alternative setting. Preparedness and ongoing assessment allow for improvement, from mere agility to agility and quality.

\section{Limitations of the Study}

This is a pioneering study that deals with the stark and rapid transition of a teacher-training college situated in northern Israel to online teaching during the Covid-19 crisis in 2020. Further studies are needed in order to deepen insights into the various aspects of this topic.

Due to the novelty of the study and the brief amount of time that has passed since the crisis, there is insufficient theoretical knowledge and research on the topic of agile transitioning of academic studies, and a teaching college in particular, to distance learning during the Coronavirus epidemic.

\section{References}

Atkinson, E. (1996). Open/flexible learning and the open learning initiative. In Proceedings of the 2nd International Conference on Open Learning, Brisbane (pp. 45-48). 4-6 December 1996. Brisbane, Qld Australia.

Davies, L., \& Bentrovato, D. (2011). Understanding education's role in fragility: Synthesis of four situational analyses of education and fragility: Afghanistan, Bosnia and Herzegovina, Cambodia, Liberia. Report by the International Institute for Educational Planning. 
Dori, Y., Hershkowitz, O., \& Kaberman, Z. (2009). Hakhshara vePituach Miktzoi shel Morim beEmtzaut Horaa veLemida Merachok keDerekh LeHitmodedut im Matzav shel Machsor Bemorim [Training and Professional Developent for Teachers via Distance Teaching and Learning as a Way to Cope with the Lack of Teachers.] Report commissioned for the expert committee entitled "Mi yelamed kshehaserim morim" ["Who will teach when there are not enough teachers?']. The Technion, Israel.

Goodarzi, B., Shakeri, K., Ghaniyoun, A., \& Heidari, M. (2018). Assessment correlation of the organizational agility of human resources with the performance staff of Tehran Emergency Center. Journal of education and health promotion, 7 .

Head, J. T., Lockee, B. B., \& Oliver, K. M. (2002). Method, media, and mode: Clarifying the discussion of distance education effectiveness. Quarterly Review of Distance Education, 3(3), 261-268.

Hecht, Y. (2018). Al ha-effectiviyut shel ha-pedogogia hamekuvenet [On the effectiveness of online pedagogy]. Iggud Ha-Internet ha-Yisraeli [The Israeli Internet Association].

Hsu, C. K., Hwang, G. J., Chuang, C. W., \& Chang, C. K. (2012). Effects on learners' performance of using selected and open network resources in a problem-based learning activity. British Journal of Educational Technology, 43(4), 606-623. https://doi.org/10.1111/j.1467-8535.2011.01235.x

Khan, B. H. (2001). Discussions of e-learning dimensions. Online Journal of education, technology and politics. Retrieved from http://www.intervir.org/n1/khan/k1_e.htm

Liu, C. H. (2010, August). The comparison of learning effectiveness between traditional face-to-face learning and e-learning among goal-oriented users. In 6th International Conference on Digital Content, Multimedia Technology and its Applications (pp. 255-260). IEEE.

Morin, R (2018) Pedagogical Agility, and Agile Methodologies, in Computer System Development Education. International Journal of Advanced Intelligence Paradigms, $11(1-2), \quad 1$. https://doi.org/10.1504/IJAIP.2018.10009419

\section{Copyrights}

Copyright for this article is retained by the author(s), with first publication rights granted to the journal.

This is an open-access article distributed under the terms and conditions of the Creative Commons Attribution license (http://creativecommons.org/licenses/by/4.0/). 